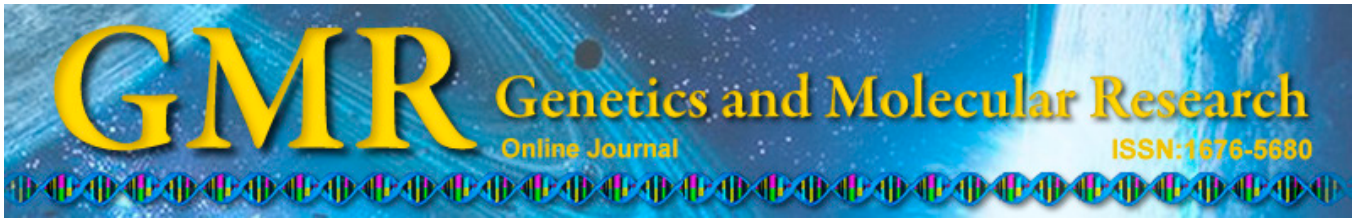

\title{
Salt stress represses production of extracellular proteases in Bacillus pumilus
}

\author{
R.F. Liu, C.L. Huang and H. Feng \\ The Key Laboratory for Bio-Resources and Eco-Environment of Ministry of \\ Education, Sichuan Key Laboratory of Molecular Biology and Biotechnology, \\ College of Life Sciences, Sichuan University, Chengdu, China \\ Corresponding author: H. Feng \\ E-mail: hfeng@scu.edu.cn
}

Genet. Mol. Res. 14 (2): 4939-4948 (2015)

Received July 29, 2014

Accepted November 24, 2014

Published May 11, 2015

DOI http://dx.doi.org/10.4238/2015.May.11.27

\begin{abstract}
Bacillus pumilus is able to secrete subtilisin-like proteases, one of which has been purified and characterized biochemically, demonstrating great potential for use in industrial applications. In the current study, the biosynthesis and transcription of extracellular proteases in B. pumilus (BA06) under salt stress were investigated using various methods, including a proteolytic assay, zymogram analysis, and real-time PCR. Our results showed that total extracellular proteolytic activity, both in fermentation broth and on milk-containing agar plates, was considerably repressed by salt in a dosage-dependent manner. As Bacillus species usually secret multiple extracellular proteases, a variety of individual extracellular protease encoding genes were selected for real-time PCR analysis. It was shown that proteases encoded by the aprE and apr $X$ genes were the major proteases in the fermentation broth in terms of their transcripts in B. pumilus. Further, transcription of aprE, aprX, and epr genes was indeed repressed by salt stress. In contrast, transcription of other genes (e.g., $v p r$ and $w p r A$ ) was not repressed or significantly affected by the salt. Conclusively, salt stress represses total extracellular proteolytic activity in B. pumilus, which can largely be ascribed to suppression of the major protease-encoding genes (aprE,
\end{abstract}


$a p r X)$ at the transcriptional level. In contrast, transcription of other protease-encoding genes (e.g., $v p r, w p r A$ ) was not repressed by salt stress.

Key words: Bacillus pumilus; Salt stress; Extracellular protease; Transcription; Real-time PCR

\section{INTRODUCTION}

Alkaline proteases are one of the most important industrial enzymes, and are largely produced by Bacillus species (Rao et al., 1998). It has been known for many years that Bacillus pumilus produces extracellular proteases (Fabian, 1970). However, it was not until 1997 that a serine alkaline protease, named protease Q, was first purified from B. pumilus (Han and Damodaran, 1997). Since then, several endopeptidases have been purified and characterized in biochemistry from various strains of B. pumilus (Aoyama et al., 2000; Huang et al., 2003; Jaouadi et al., 2008). The proteases from B. pumilus are classified into the serine protease family S8 and comprise an independent group named endopeptidase Q (Rawlings et al., 2010). Endopeptidase Q exhibits some unique catalysis properties, such as resistance to various detergents and surfactants, oxidative and thio reagents, and some organic solvents (Rahman et al., 2007; Feng et al., 2013). In addition, endopeptidase Q exhibits good thermostability (Wan et al., 2009). All of these properties indicate that endopeptidase $\mathrm{Q}$ has great potential for use in various applications. For example, the soybean-milk-coagulating enzyme is capable of coagulating soybean milk to make the traditional Japanese food "tofuyu" (Yasuda et al., 1999); DHAP (the dehairing alkaline protease) has been shown to dehair hides in the leather industry (Wang et al., 2007). However, investigations into endopeptidase Q have only focused on limited aspects, such as purification, biochemical characterization, cloning, and recombinant expression, etc.

Extracellular proteases are produced by most bacteria, mainly during the stationary growth phase (Ferrari et al., 1986), and production is usually regulated by various extracellular factors, such as sources of carbon and nitrogen, metal ions, as well as fermentation conditions (Gupta et al., 2002). Thus, medium components have been commonly optimized for production of extracellular proteases (Fakhfakh-Zouari et al., 2010). In addition, some stress factors have been shown to affect the production of proteases. For example, salt led to extensive impacts on the production of extracellular proteases in Bacillus subtilis (Kunst and Rapoport, 1995). Further, previous studies using the model $B$. subtilis 168 have revealed that production of subtilisin E (encoded by aprE) is controlled by a complex regulatory network (Abe et al., 2009) in which several regulators, such as DegU, Spo0A, SinR, and Hpr, have been identified as playing an important role (Perego and Hoch, 1988; Msadek et al., 1990; Olmos et al., 1996).

B. pumilus is recognized as being similar to the model species $B$. subtilis based on phylogenetic analysis (Berkeley et al., 2008). Using comparable genome analysis, several genes encoding putative extracellular proteases were revealed in the genome of B. pumilus (Zhao et al., 2012). In order to provide insight into the transcriptional regulation of extracellular protease genes, the production and transcription of these protease-encoding genes under salt stress were investigated in B. pumilus BA06. 


\section{MATERIAL AND METHODS}

\section{Medium and growth conditions}

B. pumilus BA06 was routinely maintained in Luria-Bertani (LB) medium (10 g tryptone, $5 \mathrm{~g}$ yeast extract, $10 \mathrm{~g} \mathrm{NaCl}$ ), and minimal medium [MM, $1 \mathrm{~L}$ containing: $10 \mathrm{~g}$ tryptone peptone, $2.0 \mathrm{~g}(\mathrm{NH} 4)_{2} \mathrm{SO}_{4}, 14.0 \mathrm{~g} \mathrm{~K}_{2} \mathrm{HPO}_{4}, 6.0 \mathrm{~g} \mathrm{KH}_{2} \mathrm{PO}_{4}, 1.0 \mathrm{~g}$ sodium citrate, 0.2 $\mathrm{g} \mathrm{MgSO}_{4} \cdot 7 \mathrm{H}_{2} \mathrm{O}, 2.5 \mathrm{~g}$ yeast extract, $5.0 \mathrm{~g}$ glucose] was used to grow the bacteria for examining the protease activity. If needed, various concentrations of $\mathrm{NaCl}$ were supplemented into the above medium.

A single colony of BA06 from an LB agar plate was inoculated into $5 \mathrm{~mL} \mathrm{LB}$, and incubated at $37^{\circ} \mathrm{C}$ overnight with vigorous shaking. Then, $0.25 \mathrm{~mL}$ of the culture was inoculated into each $50 \mathrm{~mL} \mathrm{MM}$ and $\mathrm{MM}$ supplemented with 0.4 and $0.8 \mathrm{mM} \mathrm{NaCl}$ in 250 -mL flasks. The cultures were incubated at $37^{\circ} \mathrm{C}$ with shaking at $150 \mathrm{rpm}$. During the entire experimental period, bacterial growth was monitored by measuring the adsorption value at $\mathrm{OD}_{595}$ using the spectrophotometer UV2450 (Shimadzu, Japan). In addition, $2 \mu \mathrm{L}$ of the above culture from the LB broth was also spotted on milk-containing plates with or without the addition of $\mathrm{NaCl}$. The plates were incubated at $37^{\circ} \mathrm{C}$ and the hydrolytic ring was recorded. All of the above experiments were performed in triplicate.

\section{Proteolytic activity assay}

At the indicated time points, a sample $(1.5 \mathrm{~mL})$ was taken from the above cultures, and centrifuged at $12,000 \mathrm{rpm}$ for $4 \mathrm{~min}$ at $4^{\circ} \mathrm{C}$. The supernatant served as the crucial enzyme sample for the protease activity assay. The activity assay was performed as previously described by Wan et al. (2009) with casein as a substrate. One unit (U) of enzyme activity was defined as the amount of supernatant to release $1.0 \mu \mathrm{g}$ tyrosine.

\section{Zymogram analysis}

Zymogram analysis was performed as described by Mazotto et al. (2011) but with minor modifications. Each sample of $10 \mu \mathrm{L}$ supernatant diluted with $2 \mathrm{X}$ SDS sample loading buffer without the addition of DTT or $\beta$-ME, was loaded into the wells of a $12.5 \%$ SDS-PAGE supplemented with $1 \%$ gelatin. In addition, the PageRuler Prestained Protein Ladder (Fermentas, Vilnius, Lithuania) was also loaded onto the gel. After electrophoresis, the gel was washed with deionized water after the lane of protein ladder was cut off, and then immersed in $2.5 \%$ Triton X-100 solution with shaking for $30 \mathrm{~min}$ to remove the SDS. After rinsing with deionized water three times, the gel was incubated in boric- $\mathrm{NaOH}$ buffer, $\mathrm{pH} 9.6$, at $37^{\circ} \mathrm{C}$ for $2-6 \mathrm{~h}$. The proteolytic reaction was stopped by addition of $0.1 \%$ Coomassie Blue G250. Finally, the picture was recorded after destaining.

\section{Extraction of total RNA and reverse transcription}

Total RNA of BA06 cells collected from the various cultures was extracted using RNApure Bacteria Kits (Comverse Century Company, Beijing, China) following the manufacturer protocol. RNA quality was evaluated by agarose gel electrophoresis and the ratio of 
$\mathrm{OD}_{260}$ to $\mathrm{OD}_{280}$ using a spectrophotometer.

Total RNA for each sample $(1.0 \mu \mathrm{g})$ was reversely transcribed with random hexadeoxyribonucleotide primers in a $10-\mu \mathrm{L}$ reaction mixture using the PrimeScript RT reagent kit with gDNA Eraser (TaKaRa, Dalian, China) following the manufacturer protocol. The resulting cDNA products served as the template for real-time PCR.

\section{Quantitative real-time PCR}

Real-time PCR was performed in the iQ5 Real-Time PCR System (Bio-Rad, USA) using SYBR Premix Ex PCR II (Tli RNase plus) (TaKaRa). The reaction mixture $(20 \mu \mathrm{L})$ contained $10 \mu \mathrm{L} 2 \mathrm{X}$ Master Mix, $1.0 \mu \mathrm{L}$ forward and reverse primers (10 $\mu \mathrm{M}$ in stock), and $1.0 \mu \mathrm{L}$ cDNA sample with appropriate dilution. The reaction procedure included a pre-denaturation step at $95^{\circ} \mathrm{C}$ for $2 \mathrm{~min} ; 40$ cycles of denaturation at $95^{\circ} \mathrm{C}$ for $15 \mathrm{~s}$, annealing at $60^{\circ} \mathrm{C}$ for $30 \mathrm{~s}$, and extension at $72^{\circ} \mathrm{C}$ for $30 \mathrm{~s}$. To verify the specificity of the amplification, melt curves were determined for each PCR as follows: $95^{\circ} \mathrm{C}$ for $1 \mathrm{~min}, 60^{\circ} \mathrm{C}$ for $1 \mathrm{~min}$ with the temperature rising up to $95^{\circ} \mathrm{C}$. The $16 \mathrm{~S}$ rRNA gene was used as a reference gene to normalize the real-time PCR data. The data were analyzed using the Bio-Rad iQ5 software for calculation of the molecular starting concentration and the amplification efficiencies for each real-time PCR. The transcription levels for each gene are reported as relative to $1.0 \times 10^{6}$ copies of $16 \mathrm{~S}$ rRNA. The primers for each gene are presented in Table 1.

\begin{tabular}{|c|c|c|}
\hline Target gene & Forward primer $\left(5^{\prime}-3^{\prime}\right)$ & Reverse primer $\left(5^{\prime}-3^{\prime}\right)$ \\
\hline 16S rRNA & AGCCGCGGTAATACGTAGG & ТССАСТСТССТСТTСТGСАС \\
\hline aprE & TAGCTTCGTCCCTTCAGAGCC & CTTTAACGGCATACAAGGAGGC \\
\hline $\operatorname{apr} X$ & CAAGACGATCCGATGGTGCG & GATCATCATAGGCTCGGACCG \\
\hline epr & ACAAGCGCAGTCAAGACAGC & ACCTTCGCTCGTGCGTCAC \\
\hline$v p r$ & ACCTTCGCTCGTGCGTCAC & ACCTTCGCTCGTGCGTCAC \\
\hline wprA & GAGATATCGTGTGGACACAGC & GCATCCTCTTCCTCATCACG \\
\hline
\end{tabular}

\section{RESULTS}

\section{Extracellular protease activities under salt stress}

Initially, the effect of $\mathrm{NaCl}$ on the growth of $B$. pumilus $\mathrm{BA} 06$ in the $\mathrm{MM}$ medium was examined. The results indicate that addition of $\mathrm{NaCl}$ (up to $0.8 \mathrm{M}$ ) did not yield significant impacts on the growth of BA06 (Figure 1). Under this condition, BA06 grew quickly and completed the logarithmic growth phase within approximately $24 \mathrm{~h}$, and then entered into the stationary growth phase. When $\mathrm{NaCl}$ was added up to $0.8 \mathrm{M}$ in the $\mathrm{MM}$, the cell density exhibited an obvious decline during the later stages of the stationary growth phase (after $66 \mathrm{~h}$ ).

The extracellular proteolytic activities of BA06 were monitored during the whole growth phase. Without added salt, extracellular protease activity was too low to be detected before the logarithmic growth phase $(24 \mathrm{~h})$, and then increased rapidly from $36 \mathrm{~h}$ to a peak of $225 \mathrm{U} / \mathrm{mL}$ at $54 \mathrm{~h}$ (Figure 2A). Subsequently, the activity decreased sharply, especially between 60 to $66 \mathrm{~h}$, and then remained at a very low level during the later stages of the stationary growth phase. When the MM was supplemented with salt, the synthesis of extracellular proteases by BA06 was greatly repressed and delayed (Figure 2A). With $0.4 \mathrm{M} \mathrm{NaCl}$, the peak 
in protease activity was reduced to $142 \mathrm{U} / \mathrm{mL}$ at $72 \mathrm{~h}$, with an obvious lag in comparison to that without the addition of salt. With an increase in $\mathrm{NaCl}$ up to $0.8 \mathrm{M}$, protease activity was further decreased, and remained at an extremely low level during the whole growth phase. These results demonstrate that the synthesis of extracellular proteases by B. pumilus BA06 was significantly repressed by the salt.

In order to confirm the repression of extracellular proteases by salt, plate tests were also conducted. As shown in Figure 2B, the transparent hydrolytic circles were formed by BA06 on milk-containing agar plates, especially on the second day. However, when $\mathrm{NaCl}$ was added to the agar plates, there was limited hydrolysis of the milk surrounding the colony, leading to faint circles (Figure 2B).

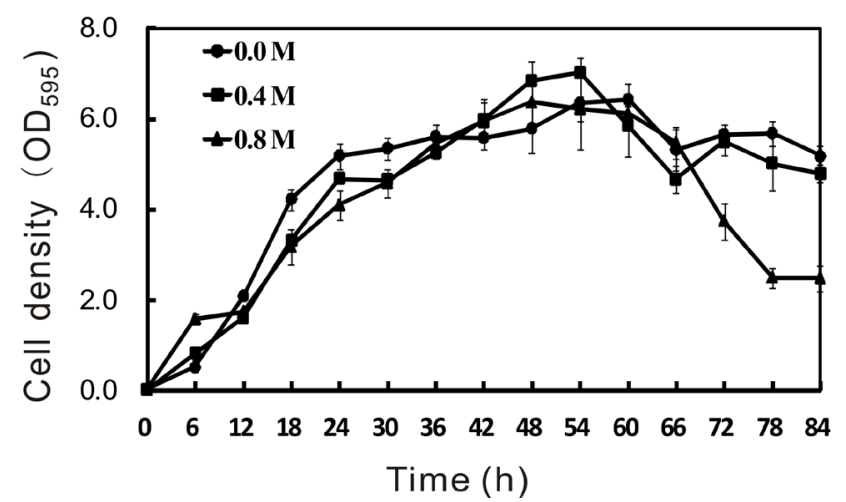

Figure 1. Growth curves of Bacillus pumilus BA06 growing in minimal medium containing $0,0.4$, and $0.8 \mathrm{M} \mathrm{NaCl}$. Cell density was measured at $\mathrm{OD}_{595}$ using a spectrophotometer. The data were derived from the average value from three independent experiments with standard errors.
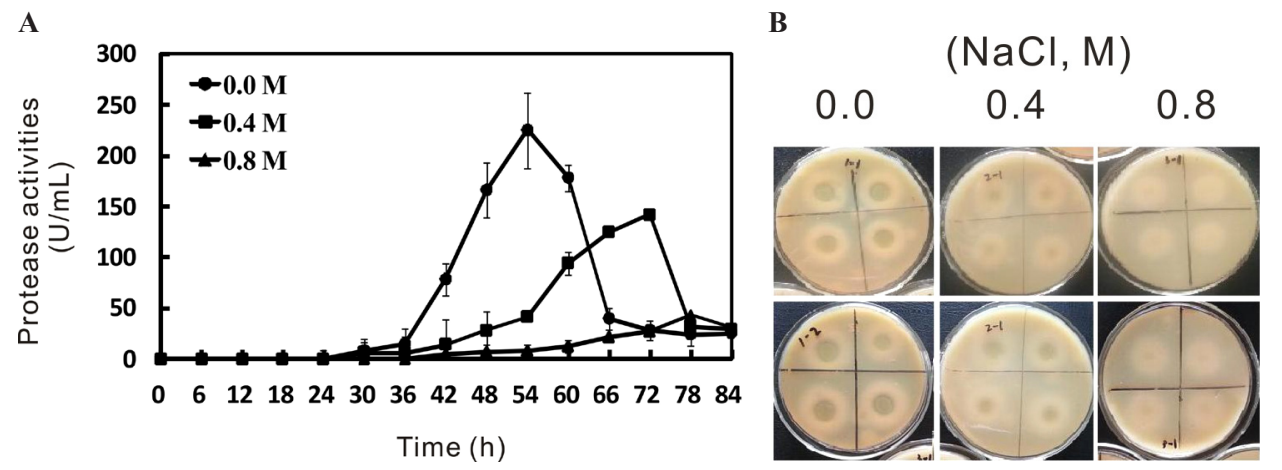

Figure 2. Repression of extracellular protease production by Bacillus pumilus BA06 following salt stress both in fermentation broth (A) and on milk-containing agar plates (B). The proteolytic activity was assayed by monitoring the release of tyrosine from casein in the supernatant samples using phenol reagent. The data were derived from the average value from three independent experiments with standard errors.

\section{Zymogram analysis of extracellular proteases under salt stress}

Since genome sequencing revealed that B. pumilus BA06 possesses several putative genes encoding extracellular proteases (Zhao et al., 2012), zymogram analysis has been per- 
formed to examine how many proteases may occur in the extracellular supernatants. As shown in a representative zymogram diagram (Figure 3), three major bands (designed as P1, P2, P3) correspond with the proteolytic activities exhibited in the supernatants from all the media, with and without the addition of $\mathrm{NaCl}$, indicating that $\mathrm{BA} 06$ is indeed able to secret multiple extracellular proteases. However, the time point and intensity of the active bands derived from the medium without $\mathrm{NaCl}$ were different from those with the addition of salt. In the MM without $\mathrm{NaCl}$, a faint active band (P1) appeared as early as $18 \mathrm{~h}$, and its intensity increased when cell growth entered the stationary growth phase. Interestingly, it was noticed that a strong active band (P1) occurred at 48 and $54 \mathrm{~h}$ in the medium without $\mathrm{NaCl}$, and then decreased suddenly (Figure $3 \mathrm{~A}$ ). In contrast, occurrence of the same band (P1) in the $\mathrm{NaCl}$ treatment $(0.4$ $\mathrm{M})$ occurred between 48 and $72 \mathrm{~h}$ with a relatively weaker intensity and diminished suddenly at $84 \mathrm{~h}$ (Figure 3B). With the addition of $0.8 \mathrm{M} \mathrm{NaCl}$, this active band was further decreased in intensity and occurred between 54 to $84 \mathrm{~h}$. The zymogram analysis demonstrates that synthesis of an extracellular protease corresponds to this active band, which was repressed and significantly delayed by the addition of salt to the growth medium.

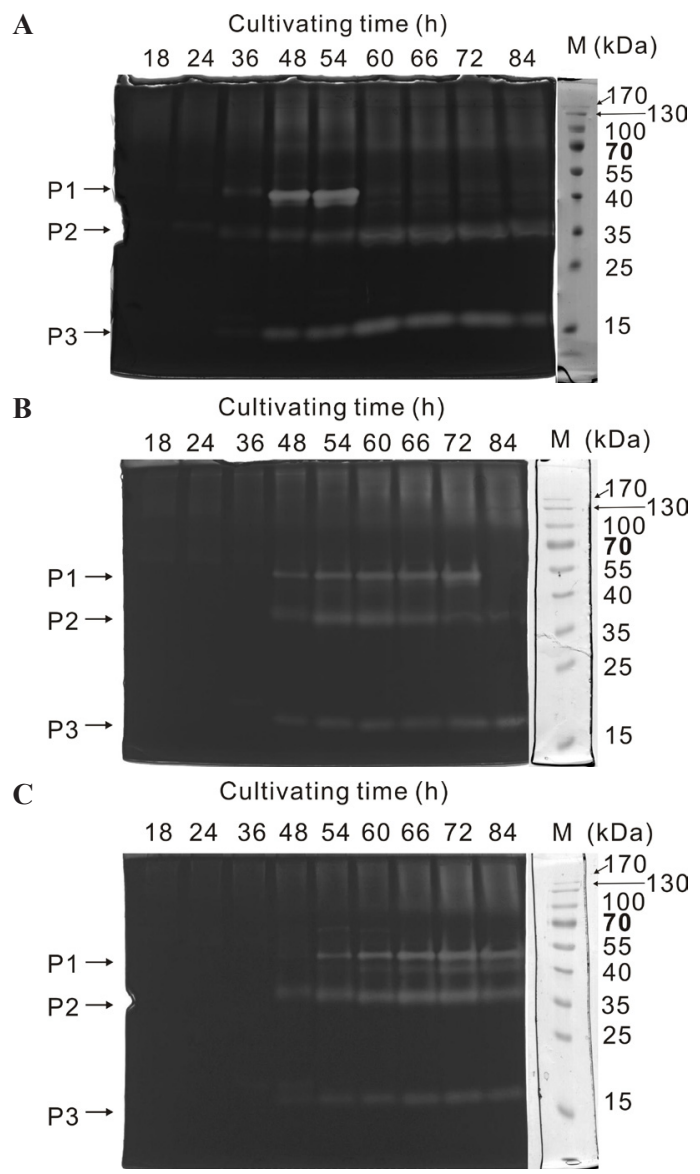

Figure 3. Zymogram analysis of the proteolytic activities towards gelatin in the supernatants of Bacillus pumilus BA06 growing in minimal medium containing $0 \mathrm{M}(\mathbf{A}), 0.4 \mathrm{M}(\mathbf{B})$, and $0.8 \mathrm{M}(\mathbf{C}) \mathrm{NaCl}$. 
The other two active bands (P2, P3) appearing in the media with and without the addition of $\mathrm{NaCl}$ lasted throughout the entire stationary growth phase, although the time points were delayed and the intensities also decreased after the addition of $\mathrm{NaCl}$ (Figure 3). In addition, a number of faint bands appeared on the gel from MM without the addition of salt, but they were diminished on the gels from the media with the addition of salt (Figure 3). However, the active bands could not be linked to the corresponding gene based on their positions on the gels.

Taken together, the extracellular proteolytic assay and zymogram analysis show that salt stress led to not only repression of the extracellular protease synthesis, but also a delay in the time required for production of the extracellular proteases by B. pumilus BA06, most likely in a dosage-dependent manner.

\section{Transcription of protease-encoding genes under salt stress}

Although the zymogram analysis showed that more than one species of extracellular protease is produced by BA06 (Figure 3), it was difficult to identify the individual band even based on the protein ladder used in the electrophoresis. According to the genome sequence (Zhao et al., 2012), the strain BA06 possesses several genes encoding extracellular protease homologous to these genes (aprE, epr, vpr, wprA, aprX) in the B. subtilis strain 168, all of which were predicated to encode proteases with a secretary signal peptide (data not shown), and their products were detected in the extracellular proteome of BA06 (Yu, 2012). Therefore, real-time PCR was applied to analyze their transcriptions under salt stress.

Based on real-time PCR analysis, aprE (encoding DHAP in B. pumilus BA06) and aprX were recognized as the major extracellular proteases, since their transcripts were 1 to 2 orders of magnitude greater than those of the other protease-encoding genes, e.g., epr, vpr (Figure 4).

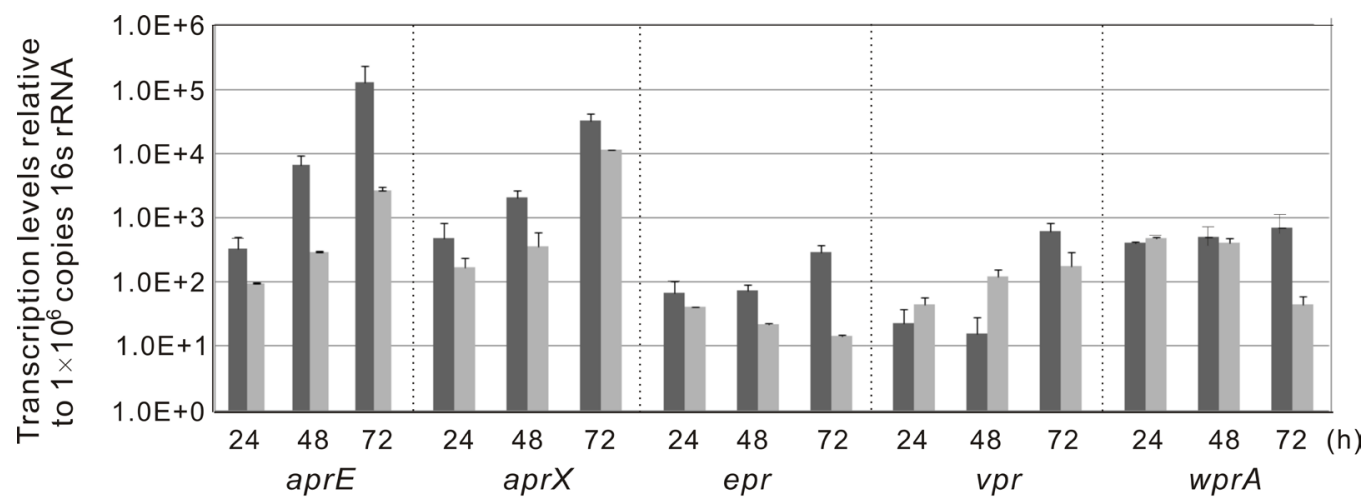

Figure 4. Transcription levels of the selected extracellular protease encoding genes in Bacillus pumilus BA06 growing under minimal medium (black column) and salt stress (gray column) conditions at different times. The mRNA levels were determined using real-time PCR and normalized to $1 \times 10^{6}$ copies of $16 \mathrm{~S}$ rRNA. The data were derived from the average value based on triple biological replicates with standard deviations.

The transcripts of aprE increased significantly from 24 to $72 \mathrm{~h}$ in both MM and MM with $\mathrm{NaCl}(0.8 \mathrm{M})$. However, addition of $\mathrm{NaCl}$ led to significant repression of the transcription of aprE (Figure 4) with fold-changes of 3.4, 22.4, and 49.3 corresponding to different time-points of 24,48 , and $72 \mathrm{~h}$, respectively. The transcription levels of the epr and aprX genes also decreased following the addition of $\mathrm{NaCl}$ (Figure 4). In contrast, transcription of 
the $v p r$ gene was upregulated by salt stress at 24 and $48 \mathrm{~h}$ (Figure 4). The $w p r A$, encoding a wall-associated serine protease in B. subtilis 168 (Margot and Karamata, 1996), seemed not to be affected by salt stress, especially in the early and mid-stationary growth phases (Figure 4). These results indicate that transcriptional responses to the salt stress were heterogeneous for various protease-encoding genes in B. pumilus BA06.

It was noticed that the transcription of many genes encoding proteolytic enzymes was constantly increasing over the experimental time course up to $72 \mathrm{~h}$. These results showed quite a significant discrepancy from the data of extracellular proteolytic activities (Figure 2A), which showed that total extracellular protease activity was much lower at $72 \mathrm{~h}$ in the MM medium.

\section{DISCUSSION}

In the current study, we investigated the effect of salt $(\mathrm{NaCl})$ on the expression of extracellular proteases at both the proteolytic activity and transcription level in B. pumilus BA06. As for some other species of Bacillus (Sharipova et al., 2008), the extracellular proteolytic activities in B. pumilus BA06 began during the early stationary growth phase ( $24 \mathrm{~h}$ ), quickly reaching a peak in the mid-stationary growth phase $(54 \mathrm{~h})$, and then declining during the later stages of the stationary phase after $66 \mathrm{~h}$ (Figure 2A). When salt was added to the medium, proteolytic activities in the supernatant were extremely repressed (Figure 2A), which was also confirmed using the plate test (Figure 2B). However, B. pumilus species encode and secret multiple proteases, thus, we attempted to determine which protease is the major one and whether all the protease-encoding genes are repressed by salt stress. Although zymogram analysis was carried out in this study, it is difficult to link the individual active band to the corresponding gene because the mature proteases are usually subject to posttranslational processing (Pflughoeft et al., 2011). Hence, real-time PCR is a good alternative to probe individual genes for this purpose. As a result, five protease-encoding genes were chosen for transcription analysis under salt stress.

Our results demonstrate that DHAP (encoded by aprE) is one of the major extracellular proteases secreted during the stationary growth phase of $B$. pumilus in terms of its transcriptional level (Figure 4), which may be the reason why this protease has been frequently purified from various strains of B. pumilus (Han and Damodaran, 1997; Huang et al., 2003). Although the individual gene that contributed to the decrease in total extracellular proteolytic activity could not be identified, aprE was assumed to be the major gene because addition of salt into the medium led to considerable transcriptional repression of this gene (Figure 4). In addition, when the aprE gene with its own promoter from Bacillus intermedius was expressed in recombinant form in $B$. subtilis, extracellular proteolytic activity was induced by salt (Sharipova et al., 2008). Accordingly, the regulation of the aprE gene may differ somehow in various Bacillus species.

The extracellular caseinolytic activity at $72 \mathrm{~h}$ in MM was greatly reduced (Figure 2A), and the transcripts of many protease-encoding genes examined in this study continued to increase up to $72 \mathrm{~h}$. Thus, an obvious gap was observed between extracellular proteolytic activity and the transcriptional level, especially during the later stages of the stationary phase $(72 \mathrm{~h})$. The reason for this could not be conclusively drawn at this stage. Perhaps, products of these genes during the later stages of the stationary growth phase were not secreted into the medium (Ruzal and SanchezRivas, 1998) or because the endospores were almost dominant in the medium at $72 \mathrm{~h}$ in B. pumilus (Shao HH and Feng H, unpublished results). Another reason may be that the extracellular proteases needed to be further processed at the posttranslational level (Pflughoeft et al., 2011). 
Bacillus species usually secrete multiple-extracellular proteases. Previous studies on transcription regulation have largely focused on the aprE gene in B. subtilis. In fact, other extracellular protease-encoding genes, such as epr, vpr, and wprA, in B. subtilis have also been shown to play some important roles in various aspects, including the processing of signal peptides, and swarming. The transcriptional response pattern of the epr and $a p r X$ genes to the salt stress was somehow similar to that of the $a p r E$ gene, whose transcription was repressed by salt, consistent with previous studies in the other Bacillus species. For example, the epr gene in $B$. subtilis was also repressed by salt stress revealed in a comprehensive transcriptome analysis (Steil et al., 2003). In contrast, another gene (vpr) showed discrepancy from the aprE gene in its transcriptional response to salt stress, as transcription was not repressed by salt, at least at some time-points (Figure 4). However, the $v p r$ gene was revealed to be repressed significantly by salt in $B$. subtilis (Hahne et al., 2010), and also repressed in a DegU-dependent manner in Bacillus megaterium (Borgmeier et al., 2011). In addition, the wprA gene in $B$. subtilis was expressed during the exponential growth phase (Margot and Karamata, 1996) and was repressed by salt stress (Hahne et al., 2010). Conclusively, the transcriptional response of these protease-encoding genes to salt stress in various Bacillus species may be different.

In conclusion, expression of the extracellular proteases in B. pumilus BA06 under salt stress was investigated. It was shown that total extracellular proteolytic activity was repressed under salt stress in a dosage-dependent manner in B. pumilus, which may be attributed to transcriptional suppression of the major protease-encoding genes caused by the salt (e.g., aprE and $a p r X$ ). In addition, other protease-encoding genes (e.g., wprA and $v p r$ ) exhibited different patterns in their transcriptional response to salt stress.

\section{ACKNOWLEDGMENTS}

to H. Feng.

Research supported by the National Natural Science Foundation of China (\#31171204)

\section{REFERENCES}

Abe S, Yasumura A and Tanaka T (2009). Regulation of Bacillus subtilis aprE expression by glnA through inhibition of sco $C$ and $\sigma^{\mathrm{D}}$-dependent $\operatorname{deg} R$ expression. J. Bacteriol. 191: 3050-3058.

Aoyama M, Yasuda M, Nakachi K, Kobamoto N, et al. (2000). Soybean-milk-coagulating activity of Bacillus pumilus derives from a serine proteinase. Appl. Microbiol. Biotechnol. 53: 390-395.

Berkeley R, Heyndrickx M, Logan N and De Vos P (2008). Applications and systematics of Bacillus and relatives. John Wiley and Sons.

Borgmeier C, Voigt B, Hecker M and Meihardt F (2011). Functional analysis of the response regulator degU in Bacillus megaterium DSM319 and comparative secretome analysis of degSU mutants. Appl. Microbiol. Biotechnol. 91: 699-711.

Fabian J (1970). Synthesis of the extracellular protease by Bacillus pumilus. Folia Microbiol. 15: 160-168.

Fakhfakh-Zouari N, Haddar A, Hmidet N, Frikha F, et al. (2010). Application of statistical experimental design for optimization of keratinases production by Bacillus pumilus A1 grown on chicken feather and some biochemical properties. Process Biochem. 45: 617-626.

Feng H, Wang H-Y and Zhang Y-Z (2013). Endopeptidase Q. In: Handbook of proteolytic enzymes (Rawlings ND and Salvesen GS, eds.). 3rd edn. Academic Press, Oxford, 3182-3188.

Ferrari E, Howard SM and Hoch JA (1986). Effect of stage 0 sporulation mutations on subtilisin expression. J. Bacteriol. 166: 173-179.

Gupta R, Beg QK and Lorenz P (2002). Bacterial alkaline proteases: molecular approaches and industrial applications. Appl. Microbiol. Biotechnol. 59: 15-32.

Hahne H, Màder U, Otto A, Bonn F, et al. (2010). A comprehensive proteomics and transcriptomics analysis of Bacillus 
subtilis salt stress adaptation. J. Bacteriol. 192: 870-882.

Han X-Q and Damodaran S (1997). Isolation, identification, and fermentation of a Bacillus species producing a detergentstable endopeptidase. J. Agric. Food Chem. 45: 4191-4195.

Huang Q, Peng Y, Li X, Wang, H, et al. (2003). Purification and characterization of an extracellular alkaline serine protease with dehairing function from Bacillus pumilus. Curr. Microbiol. 46: 169-173.

Jaouadi B, Ellouz-Chaaboum S, Rhimi M and Bejar S (2008). Biochemical and molecular characterization of a detergentstable serine alkaline protease from Bacillus pumilus CBS with high catalytic efficiency. Biochimie 90: 1291-1305.

Kunst F and Rapoport G (1995). Salt stress is an environmental signal affecting degradative enzyme synthesis in Bacillus subtilis. J. Bacteriol. 177: 2403-2407.

Margot P and Karamata D (1996). The wprA gene of Bacillus subtilis 168, expressed during exponential growth, encodes a cell-wall-associated protease. Microbiology 142: 3437-3444.

Mazotto AM, de Melo ACN, Macrae A, Rosado AS, et al. (2011). Biodegradation of feather waste by extracellular keratinases and gelatinases from Bacillus spp. World J. Microbiol. Biotechnol. 27: 1355-1365.

Msadek T, Kunst F, Henner D, Klier A, et al. (1990). Signal transduction pathway controlling synthesis of a class of degradative enzymes in Bacillus subtilis: expression of the regulatory genes and analysis of mutations in $\operatorname{deg} S$ and $\operatorname{deg}$ U. J. Bacteriol. 172: 824-834.

Olmos J, Bolaños V, Causey S, Ferrari E, et al. (1996). A functional Spo0A is required for maximal aprE expression in Bacillus subtilis. FEBS Lett. 381: 29-31.

Perego M and Hoch JA (1988). Sequence analysis and regulation of the $h p r$ locus, a regulatory gene for protease production and sporulation in Bacillus subtilis. J. Bacteriol. 170: 2560-2567.

Pflughoeft KJ, Sumby P and Koehler T (2011). Bacillus anthracis sin locus and regulation of secreted proteases. J. Bacteriol. 193: 631-639.

Rahman RN, Mahamad S, Salleh AB and Basri M (2007). A new organic solvent tolerant protease from Bacillus pumilus 115b. J. Ind. Microbiol. Biotech. 34: 509-517.

Rao MB, Tanksale AM, Ghatge MS and Deshpande VV (1998). Molecular and biotechnological aspects of microbial proteases. Microbiol. Mol. Biol. Rev. 62: 597-635.

Rawlings ND, Barrett AJ and Bateman A (2010). MEROPS: the peptidase database. Nucleic Acids Res. 38: D227-D233.

Ruzal SM and Sanchez-Rivas C (1998). In Bacillus subtilis DegU-P is a positive regulator of the osmotic response. Curr. Microbiol. 37: 368-372.

Sharipova M, Balaban N, Kayumov A, Kirillova Y, et al. (2008). The expression of the serine proteinase gene of Bacillus intermedius in Bacillus subtilis. Microbiol. Res. 163: 39-50.

Steil L, Hoffmann T, Budde I, Völker U, et al. (2003). Genome-wide transcriptional profiling analysis of adaptation of Bacillus subtilis to high salinity. J. Bacteriol. 185: 6358-6370.

Wan MY, Wang HY, Zhang YZ and Feng H (2009). Substrate specificity and thermostability of the dehairing alkaline protease from Bacillus pumilus. Appl. Biochem. Biotechnol. 159: 394-403.

Wang H, Liu DM, Liu Y, Cheng CF, et al. (2007). Screening and mutagenesis of a novel Bacillus pumilus strain producing alkaline protease for dehairing. Lett. Appl. Microbiol. 44: 1-6.

Yasuda M, Aoyama M, Sakaguchi M, Nakachi K, et al. (1999). Purification and characterization of a soybean-milkcoagulating enzyme from Bacillus pumilus TYO-67. Appl. Microbiol. Biotechnol. 51: 474-479.

Yu S-Q (2012). A comprehensive proteomic analysis of extracellular proteins of Bacillus pumilus. Master's thesis, Sichuan University, Sichuan.

Zhao CW, Wang HY, Zhang YZ and Feng H (2012). Draft genome sequence of Bacillus pumilus BA06, a producer of alkaline serine protease with leather-dehairing function. J. Bacteriol. 194: 6668-6669. 